\title{
Beyond energy expenditure: exercise and food intake regulation EI Khoury Dalia*
}

Department of Nutritional Sciences, Faculty of Medicine, University of Toronto, Toronto, ON M5S 3E2, Canada

Despite the established role of physical activity and exercise in preventing weight gain, their impact on weight loss in the absence of energy restrictions was found to be modest. There is a growing body of evidence supporting a beneficial role of exercise in energy balance and body composition. The influence of exercise on energy balance occurs not only through its modulation of energy expenditure, but also through its impact on energy intake. Various studies have explored the association between acute and chronic bouts of exercise, appetite feelings and energy intake; however, findings are controversial. Originally, it has been suggested that the relative inefficacy of exercise on weight loss originates from the partial compensation for exerciseinduced energy deficit by an increased food intake [1]. However, one research has found that only $19 \%$ of intervention studies reported an increase in energy intake after exercise, whereas $65 \%$ showed no effect and $16 \%$ showed a decrease in food intake. Indeed, most studies showed no impact of acute exercise on appetite $[2,3]$ and/or subsequent energy intake usually assessed through an ad libitum buffet meal $[1,4]$. Some have even reported reductions of hunger sensations without concomitant decreases in food intake mainly following high intensity vigorous exercise $[3,5]$.

Inconsistencies among findings have been attributed to factors including exercise characteristics, gender, nutritional state, time interval between exercise and eating and macronutrient composition of the test meal. Exercise type, duration and intensity play a significant role in defining the impact of exercise on satiety and energy intake. Some studies described exercise-induced anorexia following exercise bouts of moderate intensities and higher $(>60 \%$ of maximum oxygen uptake), characterized with decreased hunger sensations and subsequent energy intake, in obese and non-obese individuals $[5,6]$. On the other hand, exercise sessions of low to moderate intensity were shown to affect neither appetite feelings nor food intake in various studies $[5,7,8]$. When acute aerobic and resistance exercise sessions of 45 min duration were compared directly, no differences in food intake or macronutrient preferences in the post-exercise meal were observed [9]. As for duration, prolongation of aerobic exercise session of moderate intensity to a period of $120 \mathrm{~min}$, versus shorter durations of 30 or $60 \mathrm{~min}$, significantly increased food intake without any effects on hunger sensations [10]. Similar increases in food intake were observed after 2 hours of acute exercise bouts [11] and after a total of $120 \mathrm{~min}$ and not 80 min of daily exercise over 7 days [12].

The mechanisms underlying the influence of exercise on appetite and food intake are not well defined; however, a role of gut hormones is under consideration. As peptides secreted from the gastrointestinal tract such as the appetite-suppressing hormones peptide YY (PYY) and glucagon-like peptide 1 (GLP-1) and the appetite-stimulating ghrelin hormone mediate short-term feelings of hunger and satiety, various studies have examined the effects of exercise on the responses of these hormones [6,13-15]. However, research in this area is still limited. Plasma PYY concentrations were reported to be increased during aerobic exercise both in lean and obese participants $[6,14,16]$. Similarly, GLP-1 circulating levels increased during and for at least 30$60 \mathrm{~min}$ after moderate intensity exercise sessions. Increases of $\mathrm{PYY}_{3-36}$, the truncated form of PYY with an established link to appetite control, but not of GLP-1 depended on exercise intensity. Greater increases in PYY ${ }_{3-36}$ were reported following high intensity (75\% of maximum oxygen uptake) exercise of $30 \mathrm{~min}$ duration compared to both moderate intensity (50\% of maximum oxygen uptake) exercise and resting sessions of similar duration [6]. The impact of exercise on ghrelin levels is still not clear. Unchanged ghrelin circulating levels after a single exercise bout of running or cycling at moderate intensity $[14,17,18]$ and after rigorous treadmill running [19] were reported. Similarly, medium- and long-term training sessions showed no effect on ghrelin levels independent of their impact on body weight [20, 21]. However, these studies have all measured total ghrelin. When analyzing the acylated form of ghrelin, which is known for its orexigenic properties and for being more involved in appetite regulation, different responses to exercise were described. Almost all studies reported that acute exercise of moderate to high intensity suppresses circulating levels of acylated ghrelin $[6,13,15,22]$. Lowered concentrations of acylated ghrelin, which were found to determine suppressed ratings of hunger, were described during 8 hours of intense treadmill running $(72.2 \%$ of maximum oxygen uptake) in comparison to resting conditions [13].

Exercise interaction with appetite and food intake cannot be fully explained through variations in gut hormone responses to exercise. Kinetics of secretions of each hormone might differ among types and intensities of exercise as well as nutrient stimuli, and they might play differential roles for appetite regulatory processes during exercise [23]. The release of these hormones, in addition to being directly stimulated by luminal nutrients, is under the influence of both neural and endocrine factors. Furthermore, alterations in hormonal responses to exercise may play a role in preventing any increase in energy intake in response to increased energy expenditure rather than inhibiting absolute food intake. Additional mechanisms need to be further explored. Various physiological (other appetite-related hormones), psychological (cognitive factors and dietary restraint) and other factors (gender, body weight and body composition) collectively determine overall appetite and amount of energy intake after exercise and should be deeply investigated [24]. On the other hand, most of the published studies have been performed in normal weight individuals and over short-term. In order to clearly establish a beneficial role of chronic exercise in appetite control, additional long-term studies should be conducted in overweight and obese populations in order to determine whether measures of appetite and food intake are dependent or not on weight loss if induced by repetitive exercise and whether these measures predict changes in body weight following long-term training sessions. Understanding the exact role of exercise in satiety and

*Corresponding author: El Khoury Dalia, Department of Nutritional Sciences, Faculty of Medicine, University of Toronto, Toronto, ON M5S 3E2, Canada, E-mail: dalia.elkhoury@utoronto.ca

Received August 22, 2012; Accepted August 24, 2012; Published August 25, 2012

Citation: Dalia EK (2012) Beyond energy expenditure: exercise and food intake regulation. Single Cell Biol 1:e114. doi:10.4172/2168-9431.1000e114

Copyright: (c) 2012 Dalia EK. This is an open-access article distributed under the terms of the Creative Commons Attribution License, which permits unrestricted use, distribution, and reproduction in any medium, provided the original author and source are credited. 
food intake regulation is critical as it is needed to establish evidence regarding the benefits of exercise in facilitating weight loss in obesity and in optimizing body weight and thus performance of sportsmen and women in specific types of competitive sports.

\section{References}

1. Blundell JE, King NA (1999) Physical activity and regulation of food intake: current evidence. Med Sci Sports Exerc 31: S573-83.

2. King NA, Snell L, Smith RD, Blundell JE (1996) Effects of short-term exercise on appetite responses in unrestrained females. Eur J Clin Nutr 50: 663-667.

3. Imbeault $\mathrm{P}$, Saint-Pierre $\mathrm{S}$, Alméras N, Tremblay A (1997) Acute effects of exercise on energy intake and feeding behaviour. $\mathrm{Br} \mathrm{J}$ Nutr 77: 511-521.

4. King NA, Lluch A, Stubbs RJ, Blundell JE (1997) High dose exercise does not increase hunger or energy intake in free living males. Eur J Clin Nutr 51: 478483.

5. King NA, Burley VJ, Blundell JE (1994) Exercise-induced suppression of appetite: effects on food intake and implications for energy balance. Eur J Clin Nutr 48: 715-724.

6. Ueda SY, Yoshikawa T, Katsura Y, Usui T, Nakao H, et al. (2009) Changes in gut hormone levels and negative energy balance during aerobic exercise in obese young males. J Endocrinol 201: 151-159.

7. Kissileff HR, Pi-Sunyer FX, Segal K, Meltzer S, Foelsch PA (1990) Acute effects of exercise on food intake in obese and nonobese women. Am J Clin Nutr 52: 240-245.

8. Pomerleau M, Imbeault P, Parker T, Doucet E (2004) Effects of exercise intensity on food intake and appetite in women. Am J Clin Nutr 80: 1230-1236.

9. Balaguera-Cortes L, Wallman KE, Fairchild TJ, Guelfi KJ (2011) Energy intake and appetite-related hormones following acute aerobic and resistance exercise. Appl Physiol Nutr Metab. 36: 958-66.

10. Erdmann J, Tahbaz R, Lippl F, Wagenpfeil S, Schusdziarra V (2007) Plasma ghrelin levels during exercise - effects of intensity and duration. Regul Pept 143: 127-135

11. Verger $P, \quad$ Lanteaume $M T, \quad$ Louis-Sylvestre J Free food choice after acute exercise in men. Appetite 22: 159-164.

12. Stubbs RJ, Sepp A, Hughes DA, Johnstone AM, King N, et al. (2002) The effect of graded levels of exercise on energy intake and balance in free-living women. Int J Obes Relat Metab Disord 26: 866-869.

13. Broom DR, Stensel DJ, Bishop NC, Burns SF, Miyashita M (2007) Exerciseinduced suppression of acylated ghrelin in humans. J Appl Physiol 102: 21652171

14. Martins C, Morgan LM, Bloom SR, Robertson MD (2007) Effects of exercise on gut peptides, energy intake and appetite. J Endocrino 193: 251-258.

15. Broom DR, Batterham RL, King JA, Stensel DJ (2009) Influence of resistance and aerobic exercise on hunger, circulating levels of acylated ghrelin, and peptide $Y Y$ in healthy males. Am J Physiol Regul Integr Comp Physiol 296: R29-35.

16. Ueda SY, Yoshikawa T, Katsura Y, Usui T, Fujimoto S (2009) Comparable effects of moderate intensity exercise on changes in anorectic gut hormone levels and energy intake to high intensity exercise. J Endocrinol 203: 357-64.

17. Schmidt A, Maier C, Schaller G, Nowotny P, Bayerle-Eder M et al. (2004) Acute exercise has no effect on ghrelin plasma concentrations. Horm Metab Res 36: 174-177.

18. Pomerants T, Tillmann V, Karelson K, Jürimäe J, Jürimäe T (2006) Ghrelin response to acute aerobic exercise in boys at different stages of puberty. Horm Metab Res 38: 752-757.

19. Kraemer RR, Durand RJ, Acevedo EO, Johnson LG, Kraemer GR, et al. (2004) Rigorous running increases growth hormone and insulin-like growth factor-I without altering ghrelin. Exp Biol Med (Maywood) 229: 240-246.

20. Foster-Schubert KE, McTiernan A, Frayo RS, Schwartz RS, Rajan KB (2005) Human plasma ghrelin levels increase during a one-year exercise program. J Clin Endocrinol Metab 90: 820-825.

21. Mackelvie KJ, Meneilly GS, Elahi D, Wong AC, Barr SI, et al. (2007) Regulation of appetite in lean and obese adolescents after exercise: role of acylated and desacyl ghrelin. J Clin Endocrinol Metab 92: 648-654.

22. Marzullo P, Salvadori A, Brunani A, Verti B, Walker GE, et al. (2008) Acylated ghrelin decreases during acute exercise in the lean and obese state. Clin Endocrinol (Oxf) 69: 970-971.

23. Huda MS, Wilding JP, Pinkney JH (2006) Gut peptides and the regulation of appetite. Obes Rev 7: 163-182.

24. Martins C, Morgan L, Truby $H$ (2008) A review of the effects of exercise on appetite regulation: an obesity perspective. Int J Obes (Lond) 32: 1337-1347. 